\title{
Heterotopic Hepatic Polyp Identified in the Right Atrium
}

\author{
Sinan Sarsam ${ }^{a}$, Camelia Arsene ${ }^{\mathrm{a}, \mathrm{c}}$, Kamal Abu-Rashed ${ }^{\mathrm{a}}$, \\ Qinghui Liu ${ }^{\mathrm{a}}$, Ramegowda Rajagopal ${ }^{\mathrm{b}}$
}

\begin{abstract}
Heterotopic liver tissue has been described in the literature, more commonly observed in the abdominal cavity than in the thoracic cavity. In most reported supradiaphragmatic ectopic liver cases, there was a pedicle passing through the diaphragm and connecting the liver with the ectopic tissue. We report a case of heterotopic liver tissue misdiagnosed preoperatively as atrial myxoma. A 40 yearold woman presented to the Emergency Department with recurrent acute nocturnal respiratory distress. Transthoracic echocardiogram revealed a $2 \times 2.5 \mathrm{~cm}$ floating mass in right atrium at the junction of inferior vena cava. The patient underwent sternotomy for resection of the atrial mass based on presumed diagnosis of cardiac myxoma. Pathologic examination demonstrated polypoid encapsulated benign hepatic tissue. We presented this case because it is an extremely rare condition that is commonly misdiagnosed, and is the second case to date, to the best of our knowledge, of supradiaphragmatic heterotopic liver polyp identified inside the cardiac chambers in a living adult person.
\end{abstract}

Keywords: Ectopic liver; Supradiaphragmatic liver; Diaphragm; Thorax

\section{Introduction}

Heterotopic liver is a rare entity, defined as macroscopic or

\footnotetext{
Manuscript accepted for publication April 4, 2012

${ }^{a}$ Department of Medicine, Sinai-Grace Hospital, Detroit Medical Center, Detroit, MI, USA

${ }^{\mathrm{b}}$ Department of Cardiology, Sinai-Grace Hospital, Detroit Medical Center, Detroit, MI, USA

${ }^{\mathrm{c}}$ Corresponding author: Camelia Arsene, Department of Medicine, 4 th floor, Sinai-Grace Hospital, Detroit Medical Center, 6071 West Outer Drive, Detroit, MI 48235-2624, USA. Email: carsene@dmc.org
}

doi: $10.4021 / \mathrm{jmc} 652 \mathrm{w}$ microscopic foci of liver tissue present outside of the native liver, and is more frequently in the abdominal cavity attached to various organs, like the spleen, gallbladder, pancreas, umbilical fossa, adrenals, omentum and retroperitoneum $[1,2]$. Around 100 cases of ectopic liver have been reported [3], and approximately twenty cases of supradiaphragmatic ectopic liver have been presented to date, usually located in the intrathoracic cavity and pericardium, and most of them connected to the main liver by a small pedicle that passes through the diaphragm [1-20]. To our knowledge, there are only two reported cases of ectopic liver tissue identified inside the cardiac chambers in living subjects, one being an adult case, and the other one a pediatric case $[4,5]$.

\section{Case Report}

We present a 40 year-old African American woman who was admitted to our hospital because of subacute onset of shortness of breath. She was a heavy smoker with a past medical history of hypertension. Computed Tomography (CT) scan of the chest with contrast showed no pulmonary embolism. Transthoracic echocardiogram revealed a large mobile mass in right atrium which was confirmed to be a $2 \times 2.5 \mathrm{~cm}$ mobile rounded mass in the right atrial chamber near the entrance of the inferior vena cava as shown on transesophageal

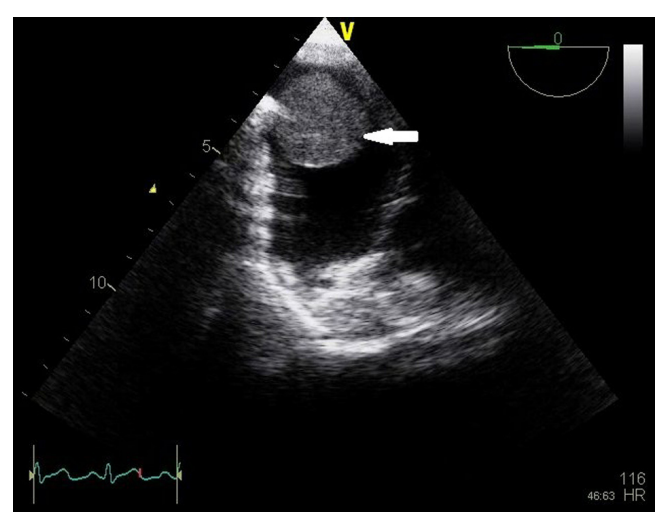

Figure 1. Transesophageal echocardiogram shows a mass in the right atrium (arrow). 


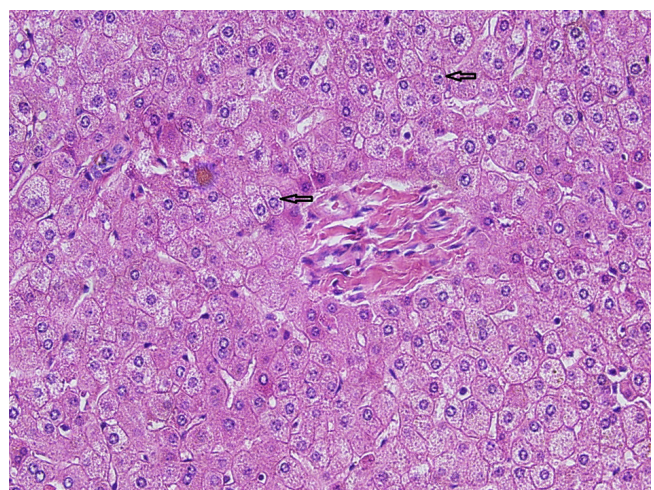

Figure 2. Histopathology section shows benign liver tissue composed of hepatocytes (arrows) forming sinusoids, central vein and portal triad. Mild periportal chronic inflammation is seen.

echocardiogram (Fig. 1).

There was a transient slight elevation of troponins without coronary stenosis shown on cardiac catheterization. The patient was taken to the operating room, and underwent sternotomy for resection of the atrial mass based on presumed diagnosis of cardiac myxoma. A right atriotomy was performed under cardiopulmonary bypass, and an $8 \mathrm{~g}, 2.8 \times 2.9$ x $2 \mathrm{~cm}$ brown-gray mass with smooth surface was excised from the right atrial wall at the junction of the inferior vena cava. Pathologic examination demonstrated polypoid encapsulated benign hepatic tissue with mild focal periportal chronic inflammation and steatosis (Fig. 2) consistent with heterotopic liver without evidence of malignancy.

\section{Discussion}

Collan et al classified ectopic liver into four types: (a) an accessory lobe of the liver of considerable size and with a connecting stalk to the liver, (b) a small accessory lobe of the liver attached to the liver, (c) ectopic liver located without connection to the liver, and (d) microscopic ectopic liver tissue (6). The case we described belongs to the third type.

Review of literature revealed a total of twenty cases of heterotopic supradiaphragmatic liver reported to date, of which some are discovered at autopsy [2,7]. Others present with pain, cough, or shortness of breath [1, 2, 7-13]. Two cases presented as intracardiac masses; the first one, described by Chapman and colleagues in a 12-year-old patient, reported an intracardiac mass causing partial obstruction of the right atrial - inferior vena caval junction [4]. The second case, described by Trocciola and colleagues reported an intracardiac mass in the right atrium at its junction with the inferior vena cava, similar to our case, but of smaller size $(1.0 \times 1.3 \mathrm{~cm})$ compared to $(2.0 \times 2.5 \mathrm{~cm})$ in our case, and originating from a hepatic vein [5].

Pathogenesis, in the presence of an intact diaphragm, is unknown, but some reports have suggested that this condi- tion mostly represents a developmental defect of the septum transversum [14]. Other possible etiologies include trauma, diaphragmatic hernia, and liver cancer metastasis [15]. The rarity of supradiaphragmatic ectopic liver makes it difficult to get the diagnosis preoperatively. It is usually misdiagnosed as atrial myxoma. Echocardiogram, CT scan or cardiac Magnetic Resonance Imaging can help further characterize the mass, but definite diagnosis requires histopathology. Treatment is surgical resection, with good outcomes. We presented this case because it is an extremely rare condition that is commonly misdiagnosed, and is the second case to date, to the best of our knowledge, of supradiaphragmatic heterotopic liver polyp identified inside the cardiac chambers in a living adult person.

\section{Acknowledgement}

None.

\section{Conflicts of Interest}

Dr. Sinan Sarsam, Dr. Kamal Abu-Rashed, Dr. Qinghui Liu, Dr. Camelia Arsene, Dr. Ramegowda Rajagopal all have no potential conflicts of interest with any companies/organizations whose products or services may be discussed in this article.

\section{Abbreviation List}

CT: Computed Tomography.

\section{References}

1. Lasser A, Wilson GL. Ectopic liver tissue mass in the thoracic cavity. Cancer. 1975;36(5):1823-1826.

2. Mendoza A, Voland J, Wolf P, Benirschke K. Supradiaphragmatic liver in the lung. Arch Pathol Lab Med. 1986;110(11):1085-1086.

3. Matsuyama M, Sugiura S, Kakita A, Sato Y, Kuroda M. Hepatocellular carcinoma arising from ectopic liver tissue in the spleen producing insulin-like growth factor II. Pathol Res Pract. 2011;207(2):124-126.

4. Chapman-Fredricks J, Birusingh R, Ricci M, Rodriguez M. Intracaval liver with cardiac extension. A new developmental anomaly? Fetal Pediatr Pathol. 2010;29(6):401-406.

5. Trocciola SM, Balsam LB, Yee H, Gianos E, Srichai MB, DeAnda A, Jr. Ectopic liver: an unexpected finding in a right atrial mass. Ann Thorac Surg. 2011;92(2):715718 . 
6. Collan Y, Hakkiluoto A, Hastbacka J. Ectopic liver. Ann Chir Gynaecol. 1978;67(1):27-29.

7. Shapiro JL, Metlay LA. Heterotopic supradiaphragmatic liver formation in association with congenital cardiac anomalies. Arch Pathol Lab Med. 1991;115(3):238-240.

8. Hansbrough ET, Lipin RJ. Intrathoracic accessory lobe of the liver. Ann Surg. 1957;145(4):564-567.

9. Sehdeva JS, Logan WD, Jr. Heterotopic (supradiaphragmatic) liver. Ann Thorac Surg. 1971;11(5):468-471.

10. Babu R, Van der Avoirt A. Ectopic intrathoracic liver. Pediatr Surg Int. 2001;17(5-6):461-462.

11. Luoma R, Raboei E. Supradiaphragmatic accessory liver: a rare cause of respiratory distress in a neonate. $\mathrm{J}$ Pediatr Surg. 2003;38(9):1413-1414.

12. Choi SU, Kim HK, Kim J. Heterotopic supradiaphragmatic liver combined with intralobar pulmonary sequestration. Ann Thorac Surg. 2008;85(5):1809-1810.

13. Jangsuk An, Joungho Han, Kyung Soo Lee, Young Soo Choi. Supradiaphragmatic Heterotopic Liver Presenting as a Pleural Mass: A case Report. Tuberc Respir Dis. 2010;69:191-195.
14. JimenezAR, Hayward RH. Ectopic liver. A cause of esophageal obstruction. Ann Thorac Surg. 1971;12(3):300-304.

15. Tsuchida Y, Yokomori K, Saito S, Kaku H, Bessho F. Stage IV-S neuroblastoma involving the liver and ectopic liver. Report of an unusual case. Cancer. 1984;53(7):1609-1611.

16. Hudson TR, Brown HN. Ectopic (supradiaphragmatic) liver. J Thorac Cardiovasc Surg. 1962;43:552-555.

17. Rendina EA, Venuta F, Pescarmona EO, Martelli M, Ricci C. Intrathoracic lobe of the liver. Case report and review of the literature. Eur J Cardiothorac Surg. 1989;3(1):75-78.

18. Kinnunen P, Kulmala P, Kaarteenaho-Wiik R, Vuopala K. Ectopic liver in the human pericardium. Histopathology. 1997;30(3):277-279.

19. Iber T, Rintala R. Intrapulmonary ectopic liver. J Pediatr Surg. 1999;34(9):1425-1426.

20. Huang CS, Hsu WH, Hsia CY. Supradiaphragmatic ectopic liver: delayed traumatic hepatic hernia mimics pulmonary tumor. Thorac Cardiovasc Surg. 2007;55(4):277278. 